Document downloaded from:

http://hdl.handle.net/10251/101917

This paper must be cited as:

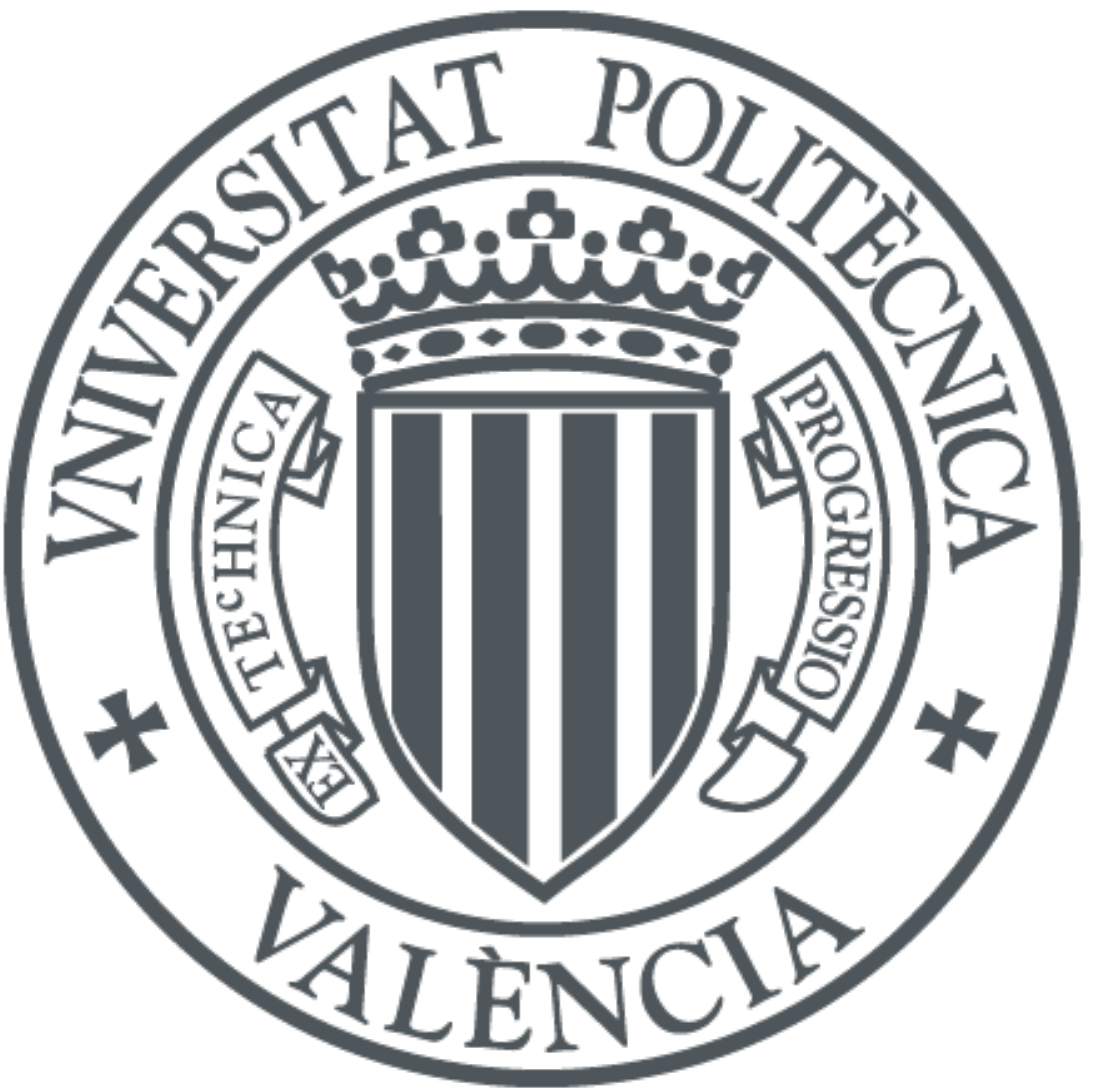

The final publication is available at

http://doi.org/10.1007/s11082-017-1219-9

Copyright Springer-Verlag

Additional Information 


\title{
Tin-mono-sulfide (SnS) Thin Films Prepared by Chemical Spray Pyrolysis with Different $[\mathbf{S}] /[\mathbf{S n}]$ Ratios
}

\author{
Thierno Sall, Miguel Mollar, Bernabé Marí* \\ Departament de Física Aplicada-IDF, Universitat Politècnica de València, Camí de Vera s/n, \\ 46022 València - Spain \\ * Corresponding author: bmari@ fis.upv.es
}

\begin{abstract}
SnS thin films were deposited by Chemical Spray Pyrolysis (CSP) using cost-effective and lowtoxicity sources materials like tin (II) chloride dihydrate and thiourea as sources of tin and sulphur, respectively. We have studied the properties of sprayed $\mathrm{SnS}$ thin films with[S]/[Sn] ratios from 1 to 4 in steps of one in order to optimize these parameters. X-ray diffraction (XRD) was used for analyzing the films structure, Raman Spectroscopy for assessing the films quality and structure, Scanning Electron Microscope (SEM) for surface morphology and Energy Dispersive Energy (EDS) for compositional element in samples, Atomic Force Microscopy (AFM) for the topography of surfaces and optical spectroscopy for measuring transmittances and then deducing the band gap energies. All films obtained are polycrystalline with (111) as preferential direction for films with $[\mathrm{S}] /[\mathrm{Sn}]$ ratio equals to one while for $[\mathrm{S}] /[\mathrm{Sn}]$ ratios from 2 to 4 the main peak becomes (101) and the (111) peak decreases in intensity. Raman spectroscopy confirms the presence of only one $\mathrm{SnS}$ phase without any additional parasite secondary phases. SEM images revealed that films are well adhered onto glass surface with rounded grain. AFM confirms this result being films with $[\mathrm{S}] /[\mathrm{Sn}]=1$ the roughest and also with the largest grain size. EDS results show an improvement of stoichiometry with the increase of the $[\mathrm{S}] /[\mathrm{Sn}]$ ratio. From optical analysis, it is inferred that the band gap energy decreases from 1.83 to $1.77 \mathrm{eV}$ when the $[\mathrm{S}] /[\mathrm{Sn}]$ ratio changes from 2 to 4.
\end{abstract}

Keywords: Sulfides; Tin Sulfide; Thin films; X-ray diffraction; Atomic force microscopy. 


\section{Introduction}

There are several binary earth abundant semiconductor materials such as $\mathrm{SnS}, \mathrm{SnSe}, \mathrm{Cu}_{2} \mathrm{~S}, \mathrm{ZnS}$, etc. well suited to be used as new photovoltaic materials for making cheaper and more efficient solar cells. Tin monosulfide ( $\mathrm{SnS}$ ), which belongs to IV-VI group semiconductors, has recently focused the attention of many researchers because of its appropriate optoelectronic properties for photovoltaic applications. It has a direct band gap near to $1.3 \mathrm{eV}$ [1], which is close to optimal band gap (1.5 eV) of solar cells and has high absorption coefficient $\left(\alpha>10^{4} \mathrm{~cm}^{-1}\right)$ [2]. Further all components of SnS are abundant, cost-effective and less toxic compared to the cadmium of $\mathrm{CdS}$ or lead in the $\mathrm{PbS}$ thin films. SnS has also p-type electrical conductivity and it has a theoretical high efficiency greater than 24\% [3]. However, nowadays despite many efforts, solar cells based on $\mathrm{SnS}$ absorber have only achieved conversion efficiency about 1.3 $\%$ [4]. Recent studies based on numerical simulations of SnS/CdS solar cells predicts that using the optical and electrical characteristics of $\mathrm{SnS}$ thin films available in the literature photoconversion efficiencies of about $10 \%$ will be obtained [5]. This low performance in both experimental and simulated photovoltaic devices may be due to impurities and/or defects in $\mathrm{SnS}$ layers that result from the preparation methods used to make the thin films for cell fabrication. Even though, $\mathrm{SnS}$ is a potential candidate for use as absorber material in thin films photovoltaic solar cells as the optoelectronic properties of the material improves.

Tin monosulfide has been prepared using various techniques like Successive Ionic Layer Adsorption and Reaction (SILAR) [6], Chemical Bath Deposition (CBD) [7], Electrochemical Deposition (ECD)[8], Atomic Layer Deposition (ALD)[9], Chemical Spray Pyrolysis (CSP)[10] etc. Chemical Spray Pyrolyis (CSP) was used in this study because it has some advantages over the others methods to prepare semiconductor thin films because it is a simple and low cost technique. In additional it is suitable for industrial scale production.

In this study, we have prepared SnS thin films by Chemical Spray Pyrolysis technique onto simple glass substrate using different $[\mathrm{S}] /[\mathrm{Sn}]$ ratios of 1-2-3 and 4. Some amount of alcohol $(10 \%)$ was added to the aqueous solvent to reduce the surface tension of water. The crystalline structure, morphology, chemical composition and optical properties of CSP-deposited SnS thin films are reported. 


\section{Experimental details}

\subsection{Films preparation}

Tin monosulfide $(\mathrm{SnS})$ thin films were prepared onto glass substrate from aqueous solution containing tin (II) chloride dihydrate $\left(\mathrm{SnCl}_{2} \cdot 2 \mathrm{H}_{2} \mathrm{O}\right)$, thiourea $\left(\mathrm{CS}\left(\mathrm{NH}_{2}\right)_{2}\right)(\geq 99 \%)$ and alcohol ( $10 \%$ in volume) to reduce the surface tension of water. The concentration of tin chloride was fixed at $0.02 \mathrm{M}$ and the $[\mathrm{S}] /[\mathrm{In}]$ ratio was varied from 1 to 4 in step of 1 . The substrate temperature was fixed to $300{ }^{\circ} \mathrm{C}$. The volume sprayed was $5 \mathrm{~mL}$, the spray rate $1.5 \mathrm{~mL} / \mathrm{min}$, the air compressed pressure 0.7 bar and the distance between the glass substrate and nozzle was kept to $25 \mathrm{~cm}$.

Glass substrates were washed in ultrasonic bath of acetone for 15 minutes, rinsed with distilled water following by washed in a bath of ethanol for 15 minutes and rinsed with distilled water before dried and used for spray.

\subsection{Films characterization}

Structural properties were characterized by means X-ray diffraction (XRD) measurements with a Rigaku Ultima IV diffractometer at the Bragg-Brentano $(\theta-2 \theta)$ configuration and using $\mathrm{CuK} \alpha$ radiation $(1.5418 \AA$ ). Structural properties were also characterized by Raman scattering measurements performed with a LabRAM HR UV spectrometer coupled to a Peltier-cooled CCD camera and using a $632.81 \mathrm{~nm}$ laser excitation line with $3 \mathrm{~cm}^{-1}$ spectral resolution.

The surface morphology and microanalysis using energy dispersive X-ray spectroscopy (EDS) were obtained on a Jeol-JSM6300 operating at $20 \mathrm{kV}$ as well as by means of an atomic force microscopy (AFM) study was done using a Bruker Multimode 8 AFM Nanoscope V controller.

Optical properties were monitored by transmittance using a Deuterium-Halogen lamp (DTMINI-2-GS Micro Park) in association with a $500 \mathrm{~mm}$ Yvon-Jobin HR460 spectrophotometer using a back-thinned Si-CCD detector (Hamamatsu) optimized for the UV-VIS range.

\section{Result and Discussion}

\subsection{X-Ray Diffraction}

The $\mathrm{SnS}$ thin films with different [S]/[Sn] ratios were prepared by chemical spray pyrolysis technique and the XRD spectra are presented in Figure 1. All films are SnS polycrystalline with orthorhombic structure and preferential orientation along (111) at $[\mathrm{S}] /[\mathrm{Sn}]=1$ while when the 
ratios increase from 2 to 4, the main peak becomes (101) and the (111) peaks decreases. We noted also others peaks like (021) and (141) for all ratios.

The variation of crystallites size with various $[\mathrm{S}] /[\mathrm{Sn}]$ ratios was calculated using the DebyeScherrer formula. We measured the FWHM for the three most intense XRD peaks $(021,101$ and 111) and then we use the average of the mentioned diffraction peaks to obtain the crystallites size. It is worth to notice that crystallites size decrease from 88 to $27 \mathrm{~nm}$ when the $[\mathrm{S}] /[\mathrm{Sn}]$ ratios varied from 1 to 4 . This reduction of crystallite size is related to the degradation of crystallinity with the augmentation of sulphur/tin ratio. Table 1 shows the variation of average crystallites size with the variation of $[\mathrm{S}] /[\mathrm{Sn}]$ ratio.

\subsection{Raman spectroscopy}

Raman spectroscopy is very important tool for studying semiconductor films structure and was used to determine second phase like $\mathrm{SnS}_{2}, \mathrm{Sn}_{2} \mathrm{~S}_{3}, \mathrm{SnO}$ or $\mathrm{SnO}_{2}$ in our films. Raman spectra of SnS thin films recorded in the range of $80-350 \mathrm{~cm}^{-1}$ are shown in Figure 2. Raman modes located at $88,107,170$ and $193 \mathrm{~cm}^{-1}$ confirm that only the SnS phase is present in our films and any other secondary phases were observed [11-12].

\subsection{Surface Morphology measured by SEM}

SEM is one of the predominant techniques to survey the surface of the films. Figure 3 shows SEM micrographs of $\mathrm{SnS}$ thin films deposited with various ratios at a fixed substrate temperature of $300{ }^{\circ} \mathrm{C}$. SEM images revealed films well covered onto glass substrate with rounded uniform grains size for all ratios and size flake like particles but those deposited with $[\mathrm{S}] /[\mathrm{Sn}]=2$ seems smaller that others ratios and the same film was denser and more compact compared to others. It is possible that the difference in morphology is caused by the effect of different concentrations of sulphur.

\subsection{Surface Topography measured by AFM}

AFM is a technique for analyzing in order to achieve a direct insight into surface topography features of films. It was used to study the evolution and the developpement of the morphological state of the sprayed $\mathrm{SnS}$ thin films as a function of thiourea concentration in $[\mathrm{S}] /[\mathrm{Sn}]$ ratio. It gives grain size and roughness of thin films. It is clear seen that the topography of our films changes with the variation of thiourea concentration in the initial solution. We notice that all films are rough with film prepared with $[\mathrm{S}] /[\mathrm{Sn}]$ ratio of 1 the most rougher with $45 \mathrm{~nm}$ and it has also the larger grain size evaluate at $247.35 \mathrm{~nm}$ than others films. When the $[\mathrm{S}] /[\mathrm{Sn}]$ ratio increases from 2 to 4 , ones noted that the roughness increases from 20.20 to $26.60 \mathrm{~nm}$ and grain 
size increases significantly at the same time from $127.5 \mathrm{~nm}$ to $222.2 \mathrm{~nm}$, respectively. The reason is that the films deposited at low $[\mathrm{S}] /[\mathrm{Sn}]$ ratio shows densely and compact films but while when the concentration of sulphur increases the coalescence and large grains increase grains boundaries which were the cause of the increase of the roughness. Table 2 shows the variation of grains size and roughness with the variation of $[\mathrm{S}] /[\mathrm{Sn}]$ ratio.

Figure 4 shows two-dimensional AFM images of $\mathrm{SnS}$ thin films prepared with different $[\mathrm{S}] /[\mathrm{Sn}]$ ratios. The difference between grain size given by AFM below and crystallites size given by XRD is explained by the fact that a grain was formed by several crystallites

\subsection{Energy Dispersive Spectroscopy Analysis (EDS)}

The Energy Dispersive X-ray Spectroscopy (EDS) is a powerful technique to analyze the chemical composition of samples based of X-ray emitted by the atoms of elements in the sample. From the Table 3 we noted that all films contain only tin ( $\mathrm{Sn})$ and sulphur (S) and when the ratio increases the stoichiometry improved with best $\mathrm{S} / \mathrm{Sn}$ ratio in films was obtained for $[\mathrm{S}] /[\mathrm{Sn}]=3$ and $[\mathrm{S}] /[\mathrm{Sn}]=4$ in the solution, which indicates that the composition of films depend on the amount of sulphur in the initial composition of the solution.

\subsection{Optical properties}

Figure 5 shows the optical transmission spectra of $\mathrm{SnS}$ thin films with various ratios in the wavelength region of 500-1000nm. In the wavelength between 500 to $650 \mathrm{~nm}$ transmittance, all films exhibited very low transmittance which was close to $0 \%$ and the transmittance increases rapidly after $650 \mathrm{~nm}$. The higher transmittance observed was $43 \%$. The low transmittance in the visible region shows clearly that $\mathrm{SnS}$ thin films are absorber layers.

Figure 6 shows band gap energy for SnS thin films obtained from optical transmission data plotting $(\mathrm{Ah} v)^{2}$ versus $\mathrm{h} v$ at various $[\mathrm{S}] /[\mathrm{Sn}]$ ratios where $\mathrm{A}$ is the absorbance and $\mathrm{h} v$ is the photon energy. When the $[\mathrm{S}] /[\mathrm{Sn}]$ ratio varied from 2 to 4 , we observe a decrease of the band gap energy from $1.83 \mathrm{eV}$ to $1.77 \mathrm{eV}$, which is higher than the gap energy of pure $\mathrm{SnS}(1.3 \mathrm{eV})$. Table 4 displays the optical band-gap values for $\mathrm{SnS}$ films synthesized from different [Sn]/[S] ratios.

The increase of the band gap energies of our samples, compared to pure $\mathrm{SnS}$ thin film which has a band gap of $1.3 \mathrm{eV}$ [1], is due to the incorporation of oxygen into samples. Assuming that the variation of band gap energy of $\mathrm{SnS}_{1-\mathrm{x}} \mathrm{O}_{\mathbf{x}}$ increases linearly with the augmentation of oxygen content, one plot a calibration curb in order to determine the amount of oxygen contended in our samples by considering as limit values band gap energies $1.3 \mathrm{eV}$ for $\mathrm{SnS}$ layer and $2.7 \mathrm{eV}$ 
(in $\mathrm{N}_{2}$ atmosphere annealing) and $3.4 \mathrm{eV}$ (in $\mathrm{O}_{2}$ atmosphere annealing) for $\mathrm{SnO}$ layer [13]. According to Figure 7, the percentage of oxygen contained in SnS layers is around $23 \pm 1 \%$ and $33 \pm 2 \%$ using $3.4 \mathrm{eV}$ and $2.7 \mathrm{eV}$, respectively, as band gap energy references for $\mathrm{SnO}$. As $\mathrm{SnS}$ films are sprayed in air the presence of oxygen in the sprayed layers are unavoidable.

\section{Conclusion}

Tin mono-sulfide (SnS) thin films have been deposited onto simple glass substrate by chemical spray pyrolysis. All deposited films are identified to be $\mathrm{SnS}$ polycrystalline with orthorhombic structure with (111) preferential peak for ratio equal to one while when the ratio increases from 2 to 4 the main peak becomes (101) and the (111) peak decreases. Raman modes confirm the presence of $\mathrm{SnS}$ phase without any additional parasite phases such as $\mathrm{SnS}_{2}, \mathrm{Sn}_{2} \mathrm{~S}_{3}, \mathrm{SnO}$ or $\mathrm{SnO}_{2}$. SEM images revealed rounded grain for all ratios and EDS analysis shows an improvement of the stoichiometry with the increase of $[\mathrm{S}] /[\mathrm{Sn}]$ ratio. AFM studies revealed that an $\mathrm{SnS}$ thin film with $[\mathrm{Sn}] /[\mathrm{S}]$ ratio equals to 1 has larger grains and higher mean roughness. The transmission in the visible region of all films was found to be very low showing the absorber character of $\mathrm{SnS}$ films. The band gap energies of $\mathrm{SnS}$ thin films prepared by chemical spray pyrolysis decrease when the $[\mathrm{Sn}] /[\mathrm{S}]$ ratios increase from $[\mathrm{S}] /[\mathrm{Sn}]=1$ and 4 . The difference between the measured optical band gap (1.77-1.83 eV) and the theoretical band gap can be explained by the incorporation of about $22-33 \%$ of oxygen into the sprayed $\mathrm{SnS}$ films. The presence of oxygen is related to the preparation method. Finally, in order to have $\mathrm{SnS}$ thin films with good characteristics for photovoltaic applications a $[\mathrm{S}] /[\mathrm{Sn}]$ ratio close to 1 seems to be the best option.

\section{Acknowledgments}

This work was supported by Ministerio de Economía y Competitividad (ENE2016-77798-C42-R) and Generalitat valenciana (Prometeus 2014/044).

\section{References}

[1] N. R. Mathews, H. B. M. Anaya, M. A. Cortes-Jacome, C. Angeles-Chavez, J. A. ToledoAntonio, Tin sulfide thin films by pulse electrodeposition: structural, morphological, and optical properties, J. Electrochem Soc. 157 (2010) H337-H341.

[2] N. Koteeswara Reddy, K. Ramesh, R. Ganesan, K. Reddy, K. R. Gunasekhar, E. Gopal, Synthesis and characterization of co-evaporated tin sulphide thin films, J. Appl. Phys. A. 83 (2006) 133-138. 
[3] J. J. Loferski, Theoretical Considerations Governing the Choice of the Optimum Semiconductor for Photovoltaic Solar Energy Conversion, J. Appl. Phys. 27 (1956) 777784.

[4] K. T. R. Reddy, N. K. Reddy, R. W. Miles, Photovoltaic properties of SnS based Solar Cells, Sol. Energ. Mater. Sol. Cells. 9 (2006) 3041-3046.

[5] H. Ullah, B. Marí, Numerical Analysis of SnS based Polycrystalline Solar Cells, Superlattices Microstruct. 72 (2014) 148-155.

[6] Gao, H. L. Shen, L. Sun, H. B. Huang, L. F. Lu, H. Cai, Preparation of SnS films with zinc blende structure by Successive ionic layer adsorption and reaction method, Mater. Lett. 64 (2010) 2177-2179.

[7] Avellaneda, M. T. S. Nair, P. K. Nair, Polymorphic Tin Sulfide Thin Films of Zinc Blende and Orthorhombic Structure by Chemical Deposition, J. Electrochem. Soc. 55 (2008) D517-D525.

[8] J. R. S. Brownson, C. Georges, C. Levy-Clement, Synthesis of $\delta$-SnS Polymorph by Electrodeposition, Chem. Mater. 12 (2007) 3080-3080.

[9] P. Sinsermsuksakul, J. Heo, W. Noh, A. S. Hock, and R. G. Gordon, Atomic Layer Deposition of Tin Monosulfide, Thin Films, Adv. Energy Mater. 1 (2011) 1116-1125.

[10] T. Sall, M. Mollar and Bernabe Marí, Substrates influences on the properties of SnS thin films deposited by chemical spray pyrolysistechnique for photovoltaic applications, J. Mater. Sci. 51(2016) 7607-7613.

[11] H. R. Chandrasekhar, R. G. Humphreys, U. Zwick and M. Cardona, Infrared and Raman spectra of the IV-VI compounds SnS and SnSe, Phys. Rev. B. 15 (1977) 2177-2183.

[12] J. Malaquias, P.A. Fernandes, P.M.P. Salome, A.F. da Cunha, Assessment of the potential of tin sulphide thin films prepared by sulphurizationof precursors as cell absorbers, Thin Solid Films 519 (2011) 7416-7420.

[13] R. Sivaramasubramaniam, M. R. Muhamad, S. Radhakrishna, Optical Properties of Annealed Tin (II) Oxide in Different Ambients, Phys. Status Silidi (a) 136 (1993) 215222. 


\section{FIGURE CAPTIONS}

Fig. 1. X-ray diffraction patterns of SnS thin films with different ratios.

Fig. 2. Raman spectroscopy analysis spectra of $\mathrm{SnS}$ prepared with different $[\mathrm{S}] /[\mathrm{Sn}]$ ratios.

Fig. 3. SEM images of SnS samples deposited by chemical spray pyrolysis with different $[\mathrm{S}] /[\mathrm{Sn}]$ ratios.

Fig. 4. Two-dimensional atomic force microscopy images of $\mathrm{SnS}$ prepared with various [S]/[Sn] ratios.

Fig. 5. Transmittance versus wavelength spectra of $\mathrm{SnS}$ prepared with different $[\mathrm{S}] /[\mathrm{Sn}]$ ratios.

Fig. 6. Plot of $(\mathrm{Ah} v)^{2}$ versus photon energy of $\mathrm{SnS}$ thin films prepared with different $[\mathrm{S}] /[\mathrm{Sn}]$ ratios.

Fig. 7. Energy band-gap versus oxygen content in $\mathrm{SnS}$ thin films prepared with different [S]/[Sn] ratios.

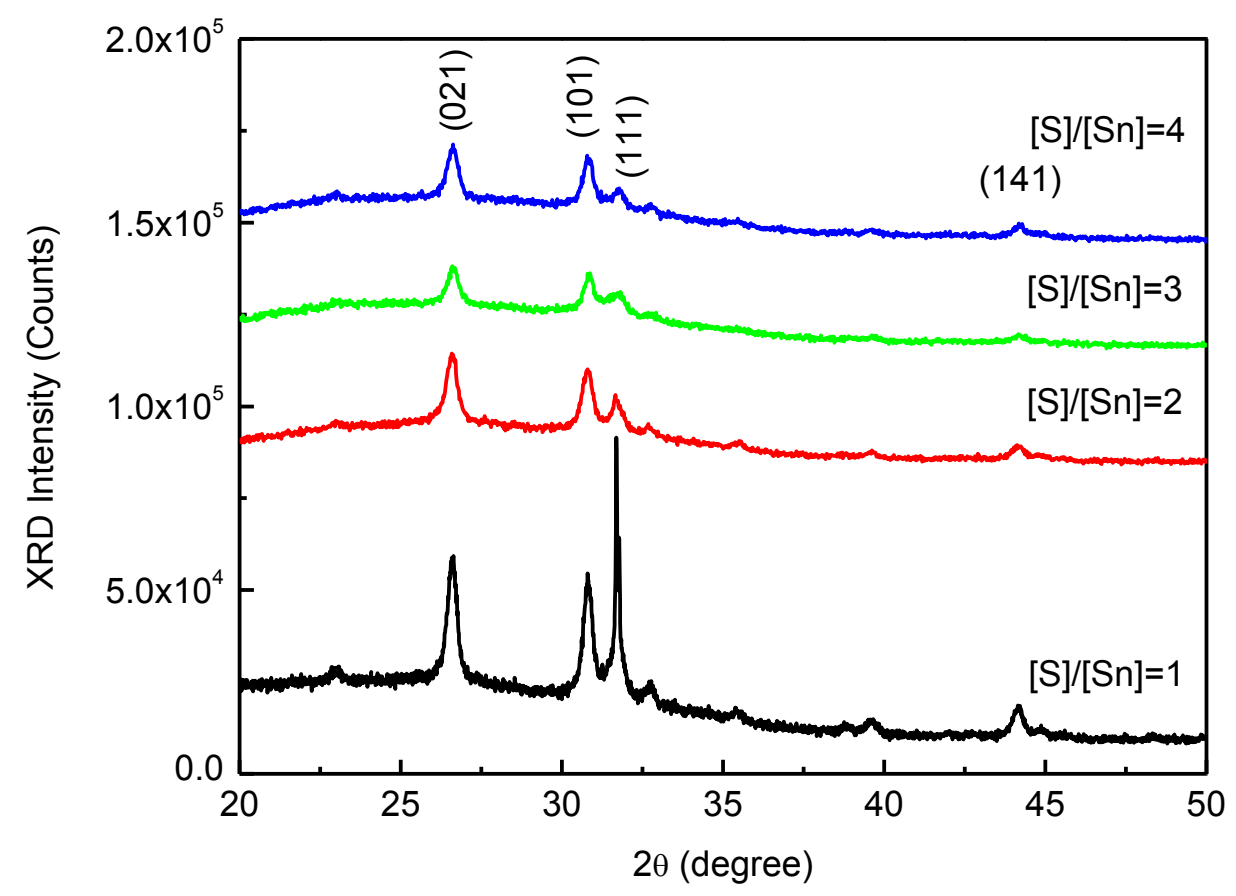

Fig. 1. X-ray diffraction patterns of SnS thin films with different ratios. 
Tin-mono-sulfide (SnS) Thin Films Prepared by Chemical Spray Pyrolysis with Different [S]/[Sn] Ratios. DOI: $10.1007 / \mathrm{s} 11082-017-1219-9$

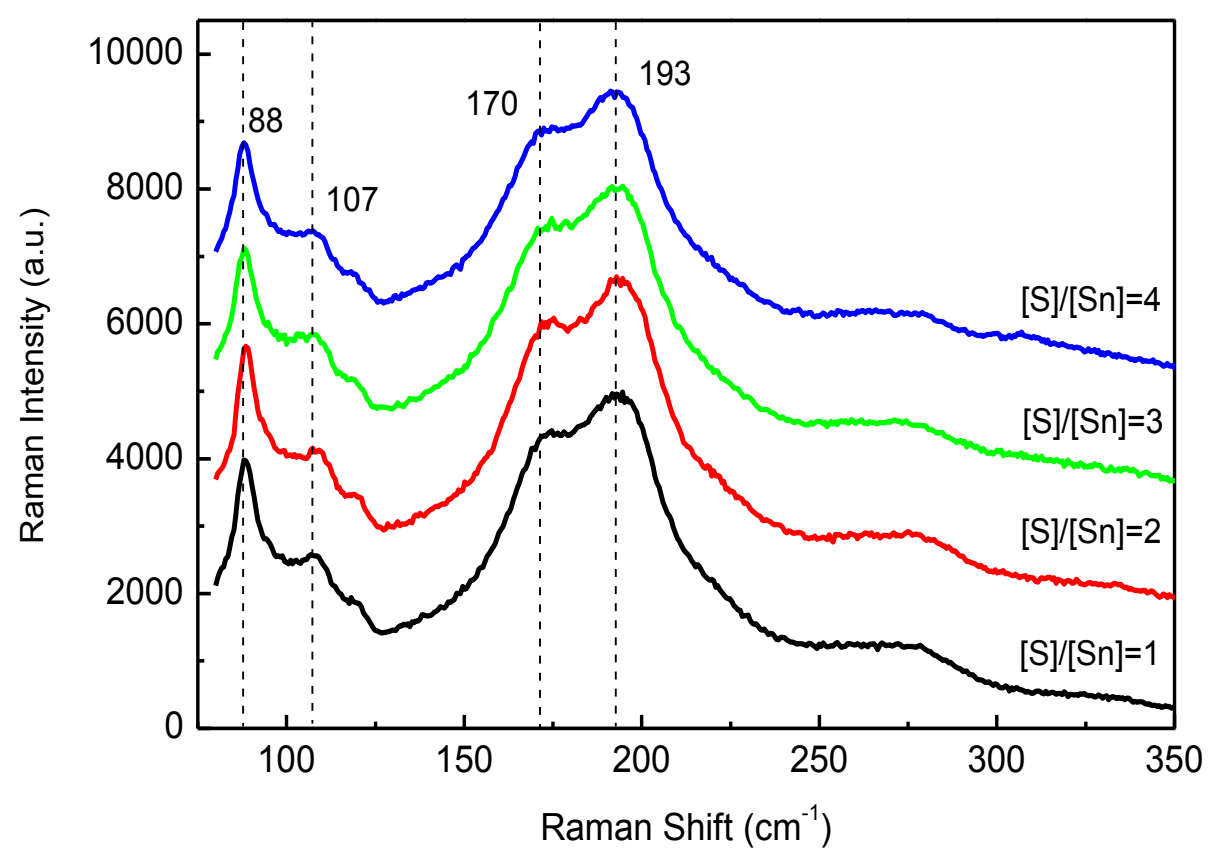

Fig. 2. Raman spectroscopy analysis spectra of $\mathrm{SnS}$ prepared with different $[\mathrm{S}] /[\mathrm{Sn}]$ ratios.
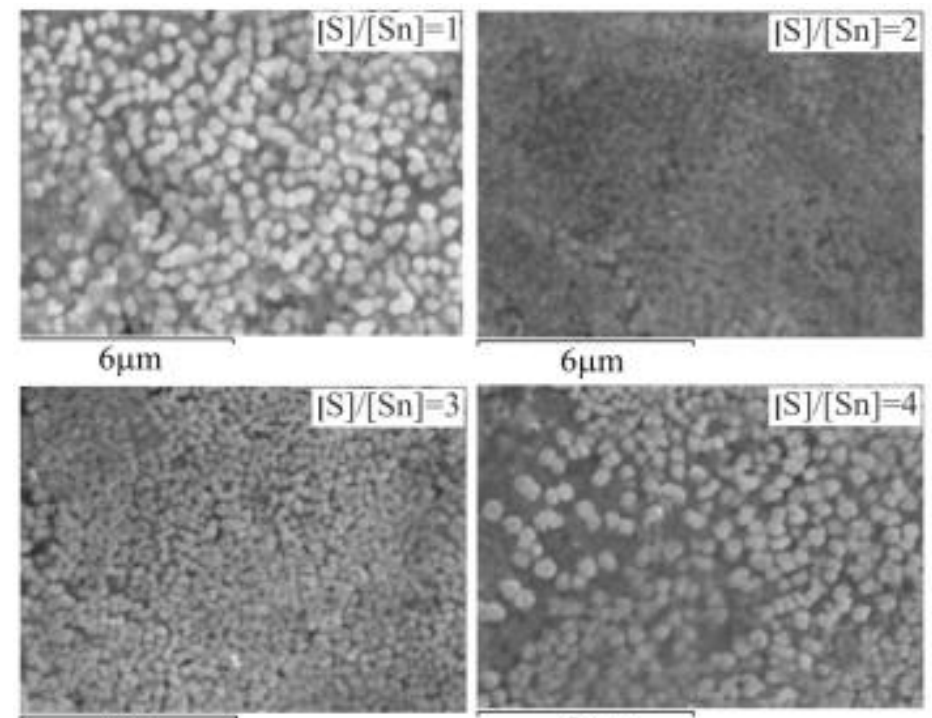

$6 \mu \mathrm{m}$

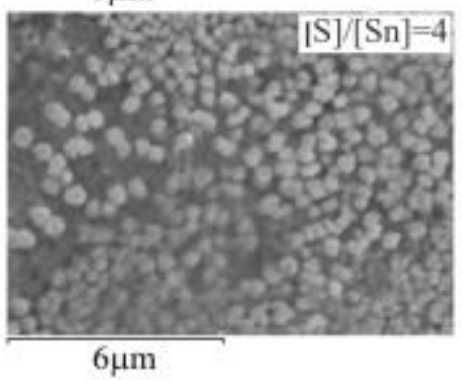

Fig. 3. SEM images of SnS samples deposited by chemical spray pyrolysis with different $[\mathrm{S}] /[\mathrm{Sn}]$ ratios. 
Tin-mono-sulfide (SnS) Thin Films Prepared by Chemical Spray Pyrolysis with Different [S]/[Sn] Ratios. DOI: $10.1007 / \mathrm{s} 11082-017-1219-9$
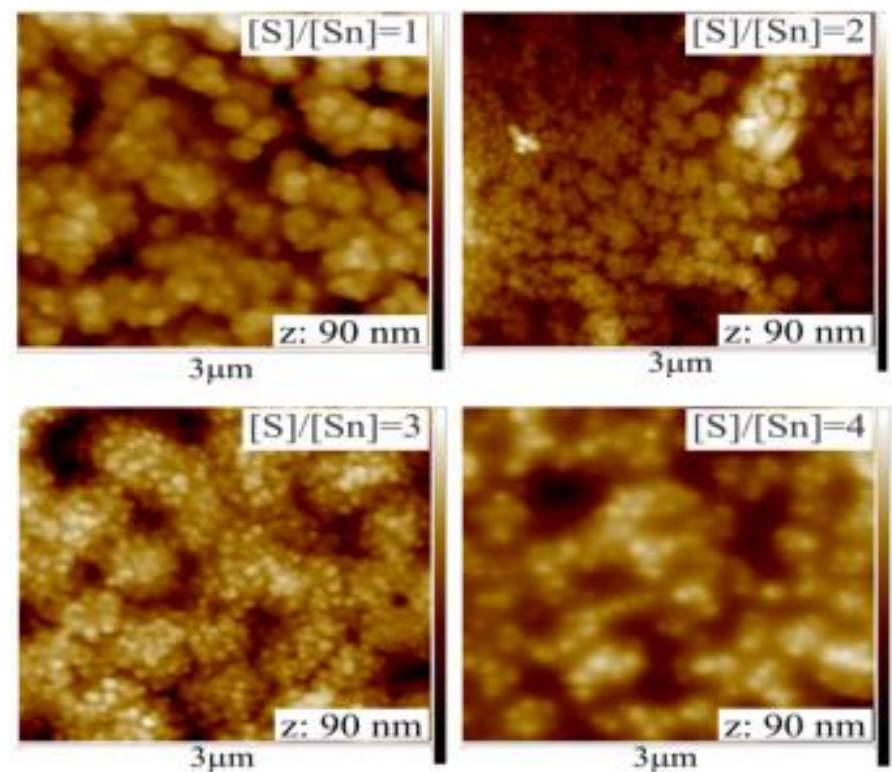

Fig. 4. Two-dimensional atomic force microscopy images of $\mathrm{SnS}$ prepared with various $[\mathrm{S}] /[\mathrm{Sn}]$ ratios.

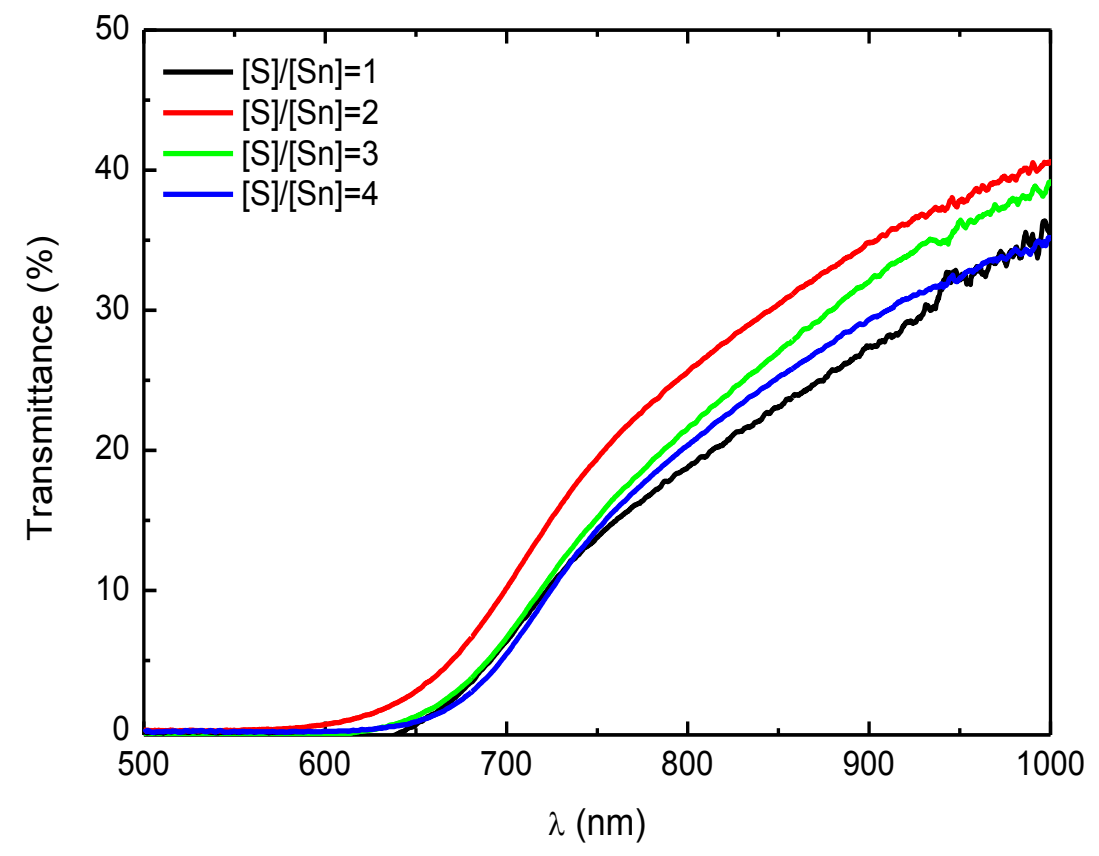

Fig. 5. Transmittance versus wavelength spectra of $\mathrm{SnS}$ prepared with different $[\mathrm{S}] /[\mathrm{Sn}]$ ratios. 
Tin-mono-sulfide (SnS) Thin Films Prepared by Chemical Spray Pyrolysis with Different [S]/[Sn] Ratios. DOI: $10.1007 / \mathrm{s} 11082-017-1219-9$

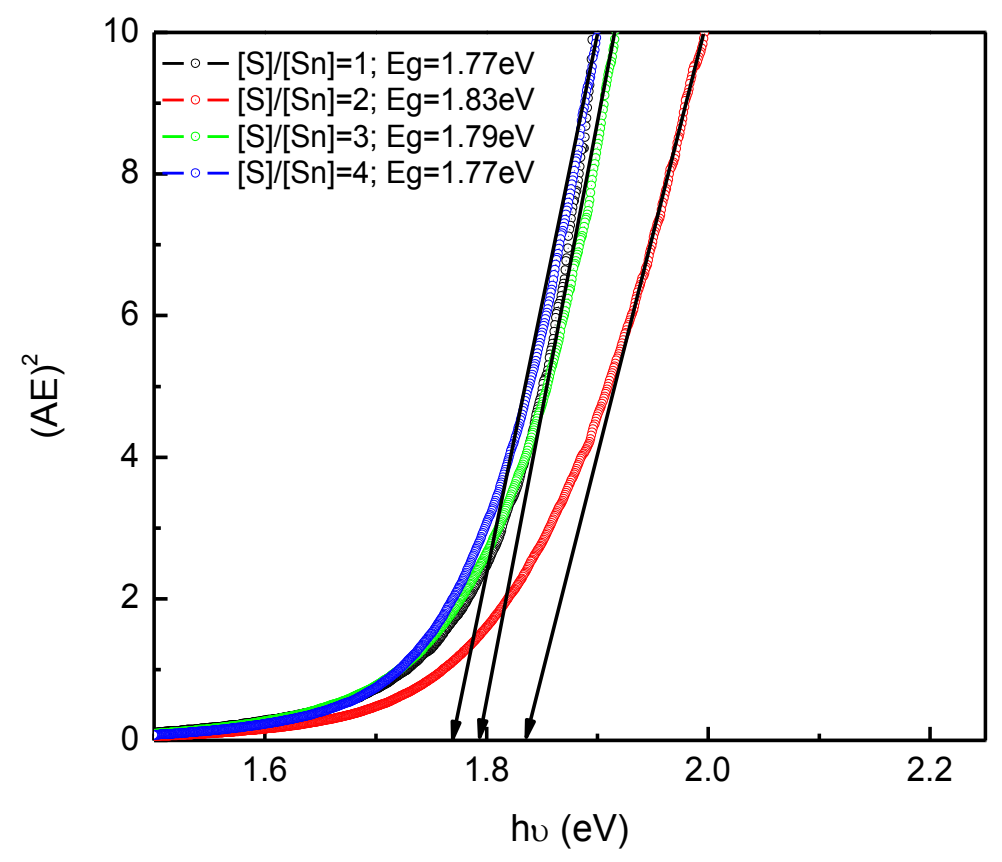

Fig. 6. Plot of $(\mathrm{Ahv})^{2}$ versus photon energy of $\mathrm{SnS}$ thin films prepared with different $[\mathrm{S}] /[\mathrm{Sn}]$ ratios.

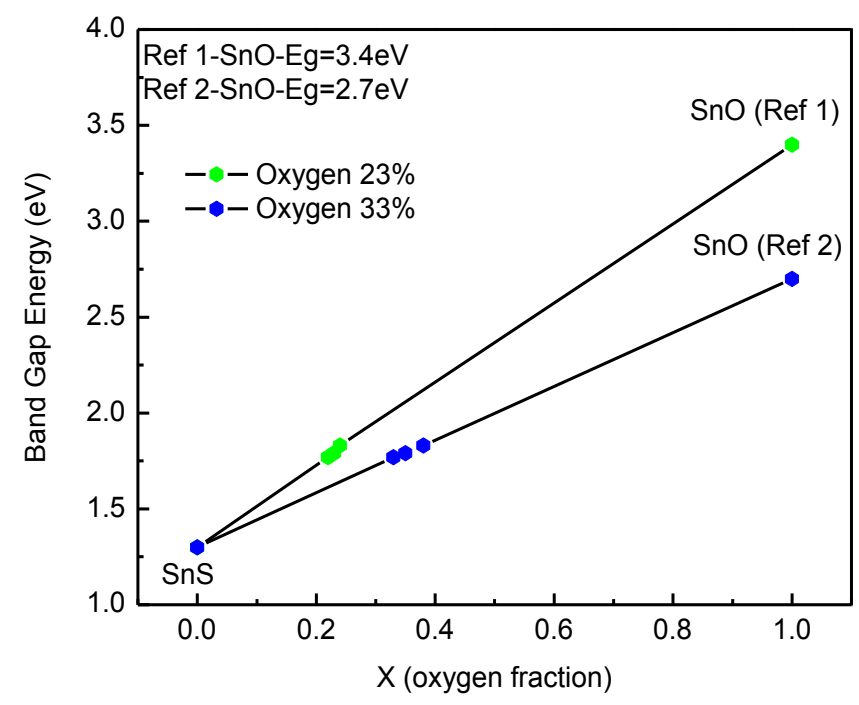

Fig. 7. Energy band-gap versus oxygen content in $\mathrm{SnS}$ thin films prepared with different $[\mathrm{S}] /[\mathrm{Sn}]$ ratios. 
Tin-mono-sulfide (SnS) Thin Films Prepared by Chemical Spray Pyrolysis with Different [S]/[Sn] Ratios. DOI: $10.1007 / \mathrm{s} 11082-017-1219-9$

\section{TABLES}

Table 1. Crystallite size of $\mathrm{SnS}$ thin films with different $[\mathrm{Sn}] /[\mathrm{S}]$ ratios.

\begin{tabular}{|c|c|}
\hline$[\mathbf{S}] /[\mathbf{S n}]$ ratio & $\mathbf{D}(\mathbf{n m})$ \\
\hline 1 & 882 \\
\hline 2 & 36.7 \\
\hline 3 & 30.5 \\
\hline 4 & 27.0 \\
\hline
\end{tabular}

Table 2. Roughness and grain size of sprayed $\mathrm{SnS}$ thin films prepared with different $[\mathrm{Sn}] /[\mathrm{S}]$ ratios

\begin{tabular}{|c|c|c|}
\hline $\begin{array}{c}{[\mathbf{S}] /[\mathbf{S n}]} \\
\text { Ratio }\end{array}$ & $\begin{array}{c}\text { Roughness } \\
(\mathbf{n m})\end{array}$ & $\begin{array}{c}\text { Grain size } \\
(\mathbf{n m})\end{array}$ \\
\hline 1 & 45.0 & 247.4 \\
\hline 2 & 20.2 & 127.5 \\
\hline 3 & 20.9 & 162.4 \\
\hline 4 & 26.6 & 222.2 \\
\hline
\end{tabular}

Table 3. Composition of SnS thin films obtained from EDS analysis.

\begin{tabular}{|c|c|c|c|}
\hline $\begin{array}{c}{[\mathbf{S}] /[\mathbf{S n}]} \\
\text { Ratio }\end{array}$ & \% S & \% Sn & S/Sn \\
\hline 1 & 42.26 & 57.74 & 0.73 \\
\hline 2 & 47.60 & 52.40 & 0.91 \\
\hline 3 & 50.14 & 49.86 & 1.00 \\
\hline 4 & 50.39 & 49.61 & 1.01 \\
\hline
\end{tabular}

Table 4. Optical band gap of $\mathrm{SnS}$ thin films prepared with various [Sn]/[S] ratios.

\begin{tabular}{|c|c|}
\hline$[\mathbf{S}] /[\mathbf{S n}]$ Ratio & $\mathbf{E g}(\mathbf{e V})$ \\
\hline 1 & 1.77 \\
\hline 2 & 1.83 \\
\hline 3 & 1.79 \\
\hline 4 & 1.77 \\
\hline
\end{tabular}

